\title{
The Impact of Community Disaster Trauma: A Focus on Emerging Research of PTSD and Other Mental Health Outcomes
}

\author{
Ju-Yeon Lee, Sung-W an Kim, and Jae-Min Kim* \\ Department of Psychiatry, Chonnam National University Medical School, Gwangju, Korea
}

\begin{abstract}
This paper reviews community residents' mental health following exposure to a community disaster trauma, with a focus on post-traumatic stress disorder (PTSD) and other mental health outcomes, such as emotional disorders, behavioral problems including addictive disorders, and personality as a maladaptive trait. This review concludes with recommendations to advance the field of community disaster research by exploring how natural and man-made disasters impact community residents across multiple domains. Moreover, this study suggests that residents impacted by community disaster trauma are frequently appropriate targets for mental health assessments or services in a community setting.
\end{abstract}

\section{Key Words: Posttraumatic Stress Disorders; Disasters; Mental Health; Personality Disorders}

This is an Open Access article distributed under the terms of the Creative Commons Attribution Non-Commercial License (http://creativecommons.org/licenses/by-nc/4.0) which permits unrestricted non-commercial use, distribution, and reproduction in any medium, provided the original work is properly cited.

\section{Article History:}

Received February 19, 2020

Revised March 4, 2020

Accepted March 5, 2020

\author{
Corresponding Author: \\ Jae-Min Kim \\ Department of Psychiatry, Chonnam \\ National University Medical School, \\ 160 Baekseo-ro, Dong-gu, Gwangju \\ 61469 , Korea \\ Tel: +82-62-220-6143 \\ Fax: +82-62-225-2351 \\ E-mail: jmkim@chonnam.ac.kr
}

\section{INTRODUCTION}

The world has faced an increasing number of natural (i.e., earthquakes, tsunamis, and flood) and man-made disasters (i.e., wars, terrorism, and industrial crises). Such disasters cause community-level traumatic reactions and generate direct social and economic costs. ${ }^{1,2}$ The mental health consequences of community trauma encompass a range of emotional, behavioral, and cognitive reactions that occur in various populations with the threat of disaster ${ }^{3,4}$ Victims have been categorized in various ways and we have divided them into three sample types in this study (Fig. 1). First, we have community residents who live in the trauma-affected area and are most directly affected by the trauma are primary victims. Second, we have community residents and significant associates of primary victims (e.g., family, close friend), local rescue workers, and residents who witnessed the trauma scene and experienced serious threats from community trauma are defined as secondary victims. Third, we defined residents who did not live in the trauma area but who experienced stress reactions due to their geographical and psychological proximity as tertiary victims. Although this group is not comprised of victims, as strictly applied in the fifth edition of the Diagnostic and Statistical Manual of Mental Disorders
(American Psychiatric Association), ${ }^{5}$ research on this group has been increasing. Previous studies on community trauma have mixed these diverse community members. Our review focuses mainly on community residents who were indirectly exposed to community trauma, including community residents who lived further away from the trauma area as secondary and tertiary victims. Secondary and tertiary victims are likely to be ignored in clinical interventions for mental health problems and psychosocial support after trauma.

Post-traumatic stress disorder (PTSD) is the most commonly studied psychopathology in the aftermath of a community disaster; ${ }^{6,7}$ thus, the objective of the present review was to present and summarize the prevalence of PTSD in community residents. This study reviews the causes and augmented mental health problems, including emotional symptoms, such as depression and anxiety, and behavioral symptoms, such as addictive and disruptive behaviors, of residents responding to community trauma. This review is a novel contribution to an existing body of studies that demonstrate findings from a large community sample exposed to trauma based on their residence. We hope to inform future research and planning aimed at supporting the mental health impact on community responders as secondary victims following trauma. 


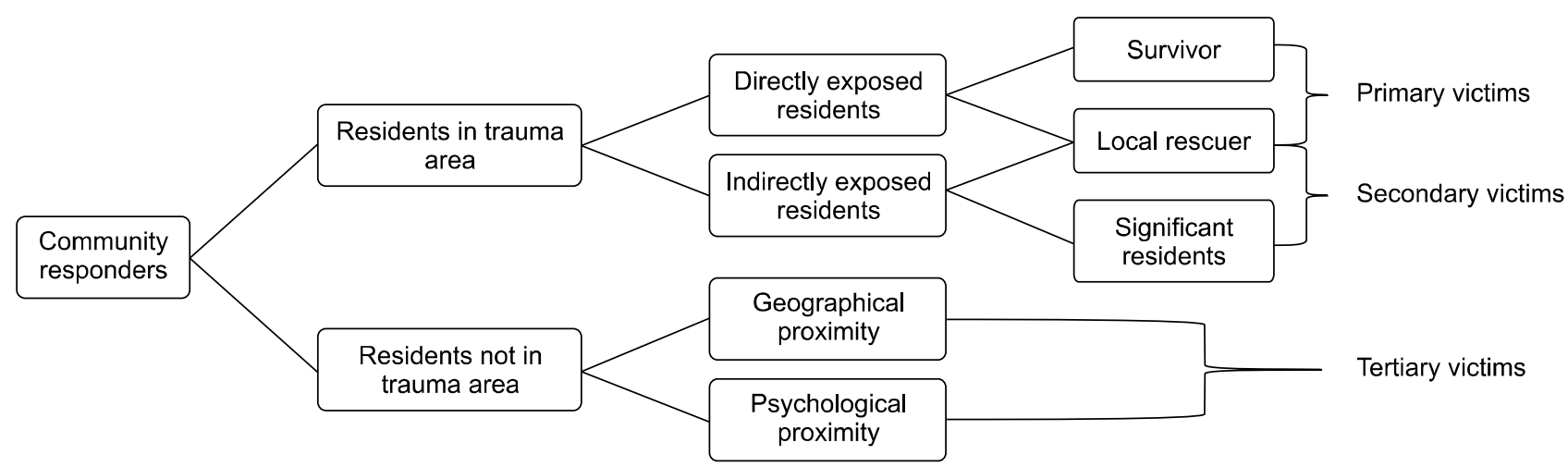

FIG. 1. Affected populations by community disaster trauma.

\section{PREVALENCE OF PTSD AFTER A COMMUNITY DISASTER TRAUMA}

Several methodological differences between investigations, samples, and scales that have been used to assess PTSD make it difficult to compare the prevalence of PTSD symptoms across studies. Furthermore, because most estimates of community mental health assessments after trauma have targeted a large community population, self-report screening instruments were applied, which may not provide valid prevalence estimates of PTSD. In particular, since mass traumatic events on the general population, such as September 11, 2001, studies have been conducted not only on directly exposed groups but also on residents living in the affected area or residing outside of the trauma area. ${ }^{8,9}$ The prevalence of PTSD after a community disaster based on recent studies ranges widely from 3.6\% to $37 \%$ among disaster-affected community residents. Community residents not directly impacted by trauma also experience vicarious trauma as a result of the disaster's impact on the community, similar to secondary trauma experienced by first responders in post-disaster situations. ${ }^{10}$ Thus, evaluating PTSD in groups who are not directly exposed is prone to overestimation, but early intervention by finding a specific group vulnerable to trauma is important for community recovery. Table 1 shows the key studies on the prevalence of PTSD and related mental health problems investigated in a large sample of community residents following exposure to community trauma since $2000 .{ }^{8,11-24}$ The prevalence of PTSD among residents after a community trauma varies due to differences in the characteristics of the trauma, sample type, and location of the residents. As there is substantial heterogeneity worldwide in the estimated prevalence of PTSD, we categorized these patients according to three aspects and reviewed the characteristics of prevalence in this context.

\section{Effects of trauma type}

Community disasters have been broadly divided into two distinct categories comprising natural (e.g., earthquakes, tsunamis, floods, hurricanes, and disease epidemics) and man-made disasters, including technological disasters (e.g., nuclear explosions and industrial accidents) and mass violence (e.g., terrorism). The prevalence of PTSD in disaster-focused studies on direct victims is estimated to be $5-60 \%$ for natural disasters and $25-75 \%$ for man-made disasters. ${ }^{6,25}$ However, the prevalence of postdisaster PTSD in the general population is much lower. In particular, this discrepancy is manifested in man-made trauma. The type of man-made trauma featured in the largest number of articles is that of terrorism, the majority of which focused on the September 11 terrorist attacks. A nationwide study of September 11 found that $17 \%$ of the US population suffered from PTSD. ${ }^{8}$ A population-based study on September 11 reported a $7.5 \%$ prevalence of PTSD in residents near the terrorist attacks. ${ }^{11}$ The prevalence of PTSD within the first year of other man-made disasters has ranged from $1-11 \%$ in the general population. ${ }^{26,27}$ Compared to natural disasters, studies on community populations exposed to man-made community trauma, which are centered on specific events and limited regions, could include a significant number of indirect victims who were affected through multiple avenues, which may contribute to the lower prevalence. However, as large-scale natural disasters can affect broad geographic areas, a substantial number of residents who are not directly affected by a disaster also experience actual damage including loss of a job or destruction of their residence and sequelae of the disaster. The prevalence of PTSD after man-made trauma tends to decrease over time in community residents. ${ }^{8,28}$ A longitudinal evaluation of PTSD prevalence in the general population after September 11 indicated that most PTSD symptoms decreased from $7.5 \%$ to $0.6 \%$ within 6 months. ${ }^{28}$ In parallel to the results of man-made disasters, some longitudinal natural disaster research has reported a decline in the prevalence of PTSD over time. ${ }^{29,30}$ However, other studies based on a community sample following a natural disaster show an increase or maintenance of PTSD prevalence over time. ${ }^{31,32}$ The factors associated with the course of PTSD include social support and cohesion, rescue effort, loss of a job, loss of property, a period of evaluation, and use of mental health facilities. ${ }^{16,29,33}$ 


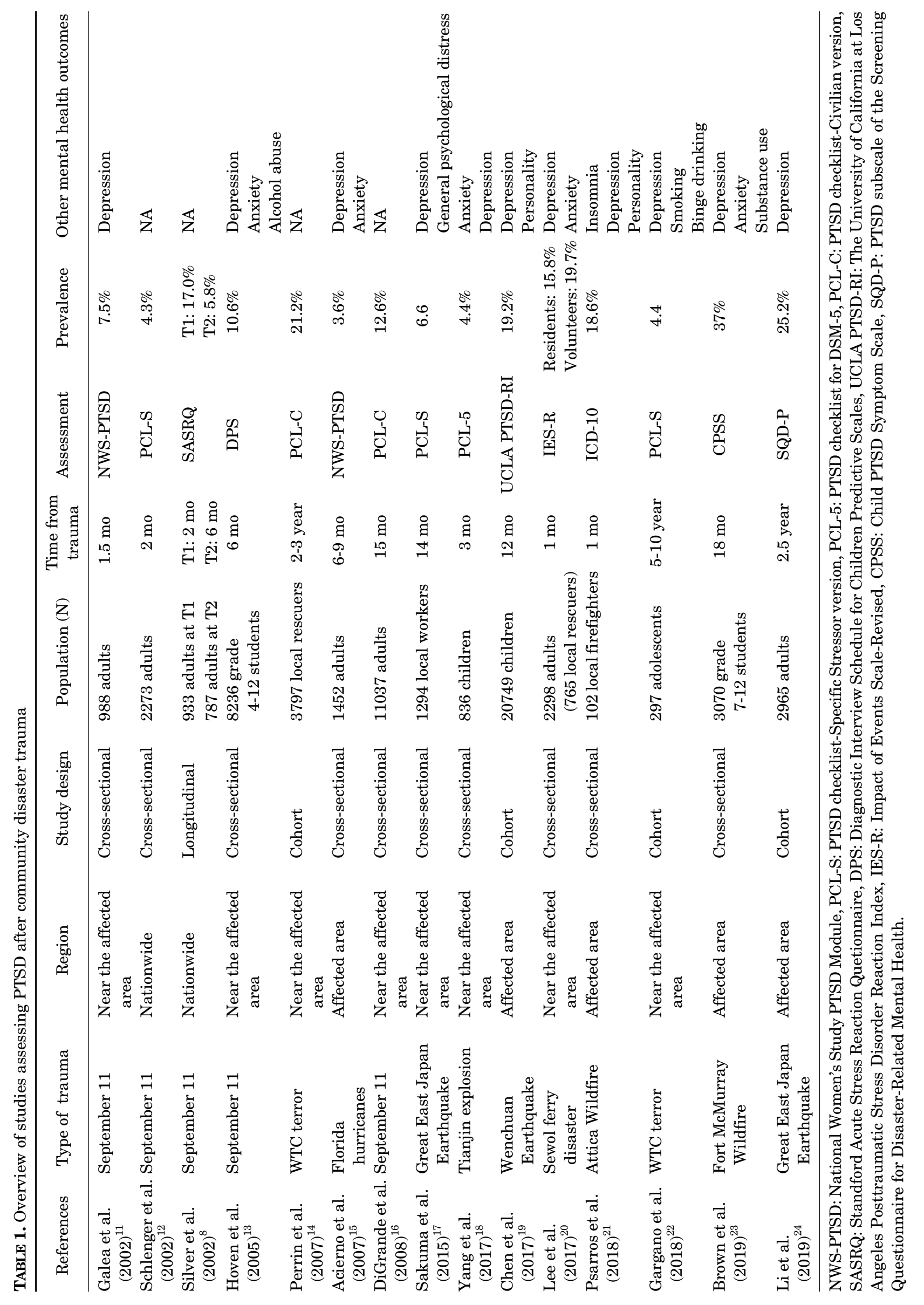




\section{Effects of sample type}

Special populations are particularly vulnerable to men tal health problems in the aftermath of a communitydisaster. Women, children, adolescents, disaster volunteers, and individuals with prior trauma or preexisting psychiatric disorders have been identified as special populations at risk. ${ }^{34}$ In this study, we review the literature of school-aged children and local rescuers in which a relatively large number of subjects have been used.

Results from several studies that have assessed PTSD in children and adolescents after a community trauma suggest that the frequency of PTSD symptoms may be greater in children than adults with similar exposure, possibly because they are in a critical developmental stage, including having immature brains. ${ }^{35,36}$ Most research suggests the importance of the child's subjective appraisal of danger in reaction to the trauma. ${ }^{37-39}$ The influence of media and visual exposure is noteworthy in the pediatric group exposed indirectly to a community disaster. The impact of the media on community trauma responses in children has been documented previously. ${ }^{40,41}$ Media exposure about terrorism is strongly associated with PTSD in children geographically distant from a disaster, who did not directly report PTSD symptoms. ${ }^{42,43}$ Directly witnessing the rescue scene following the Sewol ferry disaster in South Korea was significantly associated with PTSD in adolescents of the disaster-affected community. ${ }^{44}$ As such, subjective appraisals of danger and initial reactions to trauma through vivid imagery can predict PTSD as an objective measure of exposure in community children. Traumatic experiences in children may interact with factors in the family to affect the development of PTSD. ${ }^{45,46}$ Parental mental health and the stress response following community trauma are also related to the development of PTSD in children ${ }^{46,47}$ The magnitude of the maternal stress reactions following a major natural disaster predicts PTSD symptoms in children. ${ }^{39,48}$ There is also evidence that parental psychopathology is consistently related to children's PTSD symptoms after man-made trauma. ${ }^{46,47}$

As local rescuers play an important role in the relief of disaster-affected areas as first responders, their mental health after a large-scale trauma is a critical issue. Local rescuers are often direct victims of community trauma and, as residents, they are often troubled by the effects of trauma until the disaster recedes. First responders are an unrecognized group of "hidden" victims who are involved in community trauma. The prevalence of PTSD varies widely across different groups of rescue workers, ranging from $0 \%$ to $46 \%,{ }^{49,50}$ even when different types of rescue workers are deployed to the same disaster. ${ }^{14}$ The prevalence of PTSD among non-professional rescuers seems to be higher than that of professional rescue workers. ${ }^{6,14}$ There is a lack of knowledge in the literature on the PTSD symptoms of local rescuers. Among local workers who worked in occupations less prepared for disaster, the prevalence of PTSD in municipality workers after a large-scale natural disaster was $6.6 \%$, which is much higher than the prevalence of PTSD in firefighters $(1.6 \%) .{ }^{17}$ The prevalence of PTSD was highest in 3,797 unaffiliated volunteers among different local rescuers who lived near the site of the World Trade Center attacks. ${ }^{14}$ Local volunteers scored higher for PTSD than professionals. ${ }^{51-53}$ The prevalence of PTSD was relatively high in community volunteers compared to general residents (19.7\% vs $15.8 \%$ ) during the Sewol ferry disaster relief work. ${ }^{20}$ These results suggest that local rescuers are more vulnerable to community trauma than general populations as well as professionals.

\section{Effects of trauma location}

The proximity of the individual to the community trauma affects the expression of PTSD, regardless of the amount of exposure. It is important to identify the area where intensive assistance is necessary in cases of largescale community trauma. Several studies have indicated that geographic proximity to a community disaster is significantly related to the prevalence of PTSD symptoms. ${ }^{11,54,55}$ In particular, residing near a trauma-affected region is a strong predictor of PTSD following a community disaster. In a national study of 2,273 community populations after September 11, the prevalence of PTSD was significantly higher in New York City (11.2\%) than in other areas $(2.7-4.0 \%){ }^{12}$ Residents in areas highly exposed to September 11 were at a higher risk for PTSD compared to other areas $(20 \%$ vs. $7 \%) .{ }^{11}$ The long-term prevalence of PTSD in community residents after September 11 was consistently higher compared to that of the citywide population..$^{28}$ The relatively high prevalence of PTSD among populations close to the epicenter of a natural disaster supports the importance of geographical proximity as a contributing factor for the development of PTSD in community residents. ${ }^{56}$ These results suggest that the community environment may contribute to the development or maintenance of PTSD symptoms. However, a study of two communities exposed to continuous terror reported comparable rates of PTSD between the proximal community $(35.7 \%)$ and the remote community $(31.5 \%) .{ }^{57}$ Moreover, some studies have indicated that psychological proximity is a more important predictor of PTSD than geographical proximity. ${ }^{58}$ After the Sewol ferry disaster in Korea, the residents of Ansan, where most of the victims lived, were more severely affected by the disaster than residents of Jindo near the disaster site. ${ }^{59}$ These reports indicate that the meaning of a traumatic event, including having a personal connection to relatives of victims and worrying about the safety of someone close, is significantly associated with the development of PTSD.

\section{OTHER MENTAL HEALTH PROBLEMS AFTER COMIUUNITY TRAUMA}

Previous studies have demonstrated that PTSD with comorbid psychiatric disorders heightens the burden of mental illness, including greater functional impairment and greater risk of chronicity compared with those with only 
PTSD. ${ }^{60,61}$ The most studied comorbid psychiatric disorders after community trauma are those involving emotional problems, such as depression and anxiety. ${ }^{3,6,62,63}$ Few studies have focused on the association between community disaster exposure and behavioral problems, such as addictive symptoms and conduct problems. This study reports not only on the psychopathology, including depression and anxiety, but also on behavioral problems and cross-sectionally assessed personality as a vulnerable trait.

\section{Depression}

The prevalence of depression varies widely at $13-76 \%$ after a disaster worldwide, ${ }^{64}$ which is a much higher prevalence of depression among respondents than in the general population. Although depression might be the sole manifestation of a traumatic event, several observational studies suggest that PTSD and depression are common co-occurring conditions ranging from $48 \%$ to $55 \% .{ }^{65-67}$ An individual with PTSD and depression tends to report more severe and chronic symptoms, functional impairment, and a lower quality of life compared to those with either PTSD or depression alone. ${ }^{68-70}$ A recent cohort study of older community adults exposed to a natural disaster reported that post-disaster depression is associated with a risk of mortality, whereas PTSD is not associated with an increased risk of mortality. ${ }^{24}$ Predictors for depression after community trauma have been reported as female gender, middle or older age, lost job due to trauma, and lack of psychosocial resources. ${ }^{11,64,71}$ Personality factors, such as neuroticism, also play an important role in post-trauma depression. ${ }^{19,72}$ The severity and persistence of depressive symptoms among community trauma-exposed residents are probably related to loss of community cohesion.

\section{Anxiety}

Anxiety is among the most prevalent psychiatric symptoms reported with PTSD and depression after a disaster, but less is known about how man-made disasters are related to anxiety symptoms in communities exposed to a disaster. Generalized anxiety disorder (GAD) was observed at a $50 \%$ greater prevalence than PTSD in an epidemiologically-based study on psychological sequelae resulting from hurricanes. ${ }^{15}$ A community study on 486 adult residents after the Fort McMurray wildfire reported that GAD was significantly more prevalent following the disaster and substance use was also higher in residents with GAD. ${ }^{63}$ After the two large Nepal earthquakes in 2015, $33.8 \%$ of residents in affected areas reported high levels of anxiety and impaired functioning associated with anxiety symptoms rather than PTSD. ${ }^{73}$ Some studies have suggested that peri-traumatic panic attacks following community disaster predict an increased risk of later psychological problems. ${ }^{74}$ However, other studies suggest that peri-traumatic panic has limited predictive value for PTSD $^{75}$ and the significance of peri-traumatic panic was associated with only short-term PTSD status (i.e., 1 year). ${ }^{76}$
The prevalence of anxiety was the highest among the mental health problems of 6,132 adolescents in the most severely affected earthquake area, and insufficient sleep was independently associated with anxiety symptoms. ${ }^{77}$ In a citywide study on children exposed to September 11, the most prevalent psychopathology was an anxiety disorder, such as agoraphobia (14.8\%) and separation anxiety $(12.3 \%)$, followed by PTSD $(10.6 \%){ }^{13}$

\section{Addictive disorders}

A recent meta-analysis of substance use in the aftermath of terrorism reported that $7.3 \%$ (95\% confidence interval, 1.1-32.5\%) of a population reported increased alcohol consumption in the first 2 years following a terrorist attack. ${ }^{78}$ Several studies have reported that September 11-related PTSD symptoms among residents in the affected area subsequently resulted in binge drinking. ${ }^{79-81}$ Another study indicated a marked increase in substance (alcohol, tobacco, and cannabis) use among young residents about 18 months after an earthquake. ${ }^{82}$ Following the Canterbury earthquakes, $24 \%$ of ex-smokers relapsed into their previous smoking habit, resulting in increased smoking prevalence. ${ }^{83} \mathrm{~A}$ cross-sectional study after the Sewol ferry disaster reported that problematic internet use among children in the affected area was associated with PTSD symptoms. ${ }^{84}$ These studies suggest that people react to emotional distress by turning to addictive behaviors in the absence of other more adaptive coping strategies.

\section{Externalizing symptoms}

Although most studies on mental health outcomes after a community disaster have focused on PTSD and internalized symptoms, such as anxiety and depression, recent studies have shown the presence of externalizing symptoms, such as behavioral problems (e.g., conduct problems, aggression, and oppositionality) in a considerable proportion of youth after a community disaster. Following the 2013 Boston Marathon bombing, increased conduct problems in Boston-area children (4-19 years) were reported through their caregivers. ${ }^{85}$ Israeli adolescents exposed to recurrent terrorism reported high levels of risk-taking behaviors (fighting, stealing, disobeying, and substance use), and the severity of risk-taking was associated with greater terrorism exposure. ${ }^{86}$ Young children (4-9 years) exposed to a technological disaster developed significantly more conduct problems (hyperactivity) than controls. ${ }^{87}$ A study using data from the WTC health registry reported that many adolescents with behavioral problems after September 11 became chronic smokers. ${ }^{22}$ In addition, several studies have been performed on externalizing symptom outcomes among youth impacted by natural disasters. ${ }^{88-90}$ Several hypotheses have been proposed to explain the prevalence of such behavioral symptoms after a community disaster, including heightened activation of the stress-response system and the tendency for behavioral reenactment. $^{88,91}$ 


\section{Personality}

Personality traits can also be a contributing factor to PTSD by shaping cognitive processes, coping strategies, and the interaction with social support as a predisposing factor. ${ }^{92,93}$ A few studies have reported that neuroticism plays an important role in the development of PTSD among community residents after a trauma. However, as the majority of personality studies on PTSD symptoms in community residents are cross-sectional, the authors were unable to ascertain whether residents had been neurotic before the disaster or became neurotic because of the trauma. This finding is relevant given that personality variables in the context of mental health status that co-occur with PTSD in community residents after a community mass trauma. Previous studies of community adults following a natural disaster have suggested that residents with neurotic personalities tend to be associated with PTSD symptoms. ${ }^{94,95}$ Other research has found that neuroticism is a significant risk factor for the onset of PTSD symptoms in adolescents. ${ }^{96}$ A study on the role of personality in PTSD among children revealed that the neuroticism trait is a risk for PTSD symptoms, but that extraversion is not associated with PTSD. ${ }^{19}$ This finding in the context of a manmade disaster is in line with previous findings on natural disasters indicating that neuroticism is significantly associated with PTSD symptoms. ${ }^{97-99}$ Neuroticism is a personality trait characterized by emotional instability and anxiousness, which can cause maladaptive coping and increase susceptibility to PTSD. ${ }^{100}$

\section{CONCLUSIONS}

This review highlights the importance of conducting comprehensive population-based mental health assessments. In particular, vulnerable residents after a community trauma including local rescuers, children, and adolescents, as well as those living closest to the disaster site should be considered when targeting interventions or developing mental health preparedness protocols to mitigate PTSD. In addition, as these findings suggest important public mental health implications, we recommend consideration of a routine assessment of co-morbid mental health problems beyond PTSD after a community disaster trauma.

\section{ACKNOWLEDGEMENTS}

This study was supported by a grant (BCRI20061) Chonnam National University Hospital Biomedical Research Institute to J-MK.

\section{CONFLICT OF INTEREST STATEMENT}

None declared.

\section{REFERENCES}

1. Lebowitz AJ. Community collaboration as a disaster mental health competency: a systematic literature review. Community Ment Health J 2015;51:125-31.

2. La Greca AM, Comer JS, Lai BS. Trauma and child health: an introduction to the special issue. J Pediatr Psychol 2016;41:1-4.

3. Norris FH, Friedman MJ, Watson PJ. 60,000 disaster victims speak: part II. Summary and implications of the disaster mental health research. Psychiatry 2002;65:240-60.

4. Pietrzak RH, Tracy M, Galea S, Kilpatrick DG, Ruggiero KJ, Hamblen JL, et al. Resilience in the face of disaster: prevalence and longitudinal course of mental disorders following hurricane Ike. PLoS One 2012;7:e38964.

5. American Psychiatric Association. Diagnostic and statistical manual of mental disorders. 5th ed. Arlington:American Psychiatric Publishing,2013.

6. Neria Y, Nandi A, Galea S. Post-traumatic stress disorder following disasters: a systematic review. Psychol Med 2008;38: 467-80.

7. Ducrocq F, Vaiva G, Cottencin O, Molenda S, Bailly D. [Posttraumatic stress, post-traumatic depression and major depressive episode: literature]. Encephale 2001;27:159-68. French.

8. Silver RC, Holman EA, McIntosh DN, Poulin M, Gil-Rivas V. Nationwide longitudinal study of psychological responses to September 11. JAMA 2002;288:1235-44.

9. Calderoni ME, Alderman EM, Silver EJ, Bauman LJ. The mental health impact of 9/11 on inner-city high school students 20 miles north of Ground Zero. J Adolesc Health 2006;39:57-65.

10. McLennan J, Evans L, Cowlishaw S, Pamment L, Wright L. Secondary traumatic stress in postdisaster field research interviewers. J Trauma Stress 2016;29:101-5.

11. Galea S, Ahern J, Resnick H, Kilpatrick D, Bucuvalas M, Gold $\mathrm{J}$, et al. Psychological sequelae of the September 11 terrorist attacks in New York City. N Engl J Med 2002;346:982-7.

12. Schlenger WE, Caddell JM, Ebert L, Jordan BK, Rourke KM, Wilson D, et al. Psychological reactions to terrorist attacks: findings from the National Study of Americans' Reactions to September 11. JAMA 2002;288:581-8.

13. Hoven CW, Duarte CS, Lucas CP, Wu P, Mandell DJ, Goodwin RD, et al. Psychopathology among New York City public school children 6 months after September 11. Arch Gen Psychiatry 2005;62:545-52.

14. Perrin MA, DiGrande L, Wheeler K, Thorpe L, Farfel M, Brackbill R. Differences in PTSD prevalence and associated risk factors among World Trade Center disaster rescue and recovery workers. Am J Psychiatry 2007;164:1385-94.

15. Acierno R, Ruggiero KJ, Galea S, Resnick HS, Koenen K, Roitzsch J, et al. Psychological sequelae resulting from the 2004 Florida hurricanes: implications for postdisaster intervention. Am J Public Health 2007;97 Suppl 1:S103-8.

16. DiGrande L, Perrin MA, Thorpe LE, Thalji L, Murphy J, Wu D, et al. Posttraumatic stress symptoms, PTSD, and risk factors among lower Manhattan residents 2-3 years after the September 11, 2001 terrorist attacks. J Trauma Stress 2008;21: 264-73.

17. Sakuma A, Takahashi Y, Ueda I, Sato H, Katsura M, Abe M, et 
al. Post-traumatic stress disorder and depression prevalence and associated risk factors among local disaster relief and reconstruction workers fourteen months after the Great East Japan Earthquake: a cross-sectional study. BMC Psychiatry 2015;15:58.

18. Yang H, Wang L, Cao C, Cao X, Fang R, Zhang J, et al. The underlying dimensions of DSM-5 PTSD symptoms and their relations with anxiety and depression in a sample of adolescents exposed to an explosion accident. Eur J Psychotraumatol 2017;8: 1272789.

19. Chen X, Xu J, Li B, Li N, Guo W, Ran MS, et al. The role of personality and subjective exposure experiences in posttraumatic stress disorder and depression symptoms among children following Wenchuan earthquake. Sci Rep 2017;7:17223.

20. Lee JY, Kim SW, Bae KY, Kim JM, Shin IS, Yoon JS. Factors associated with posttraumatic stress disorder symptoms among community volunteers during the Sewol ferry disaster in Korea. Compr Psychiatry 2017;77:38-44.

21. Psarros C, Theleritis C, Kokras N, Lyrakos D, Koborozos A, Kakabakou O, et al. Personality characteristics and individual factors associated with PTSD in firefighters one month after extended wildfires. Nord J Psychiatry 2018;72:17-23.

22. Gargano LM, Locke S, Li J, Farfel MR. Behavior problems in adolescence and subsequent mental health in early adulthood: results from the World Trade Center Health Registry Cohort. Pediatr Res 2018;84:205-9.

23. Brown MRG, Agyapong V, Greenshaw AJ, Cribben I, BrettMacLean P, Drolet J, et al. Significant PTSD and other mental health effects present 18 months after the Fort Mcmurray wildfire: findings from 3,070 grades 7-12 students. Front Psychiatry 2019;10:623.

24. Li X, Aida J, Hikichi H, Kondo K, Kawachi I. Association of postdisaster depression and posttraumatic stress disorder with mortality among older disaster survivors of the 2011 Great East Japan Earthquake and Tsunami. JAMA Netw Open 2019;2: e1917550.

25. Galea S, Nandi A, Vlahov D. The epidemiology of post-traumatic stress disorder after disasters. Epidemiol Rev 2005;27:78-91.

26. Havenaar JM, Rumyantzeva GM, van den Brink W, Poelijoe NW, van den Bout J, van Engeland H, et al. Long-term mental health effects of the Chernobyl disaster: an epidemiologic survey in two former Soviet regions. Am J Psychiatry 1997;154:1605-7.

27. Smith DW, Christiansen EH, Vincent R, Hann NE. Population effects of the bombing of Oklahoma City. J Okla State Med Assoc 1999;92:193-8.

28. Galea S, Vlahov D, Resnick H, Ahern J, Susser E, Gold J, et al. Trends of probable post-traumatic stress disorder in New York City after the September 11 terrorist attacks. Am J Epidemiol 2003;158:514-24.

29. Altindag A, Ozen S, Sir A. One-year follow-up study of posttraumatic stress disorder among earthquake survivors in Turkey. Compr Psychiatry 2005;46:328-33.

30. van Griensven F, Chakkraband ML, Thienkrua W, Pengjuntr W, Lopes Cardozo B, Tantipiwatanaskul P, et al. Mental health problems among adults in tsunami-affected areas in southern Thailand. JAMA 2006;296:537-48.

31. Wang X, Gao L, Shinfuku N, Zhang H, Zhao C, Shen Y.
Longitudinal study of earthquake-related PTSD in a randomly selected community sample in north China. Am J Psychiatry 2000;157:1260-6.

32. Onder E, Tural U, Aker T, Kiliç C, Erdoğan S. Prevalence of psychiatric disorders three years after the 1999 earthquake in Turkey: Marmara Earthquake Survey (MES). Soc Psychiatry Psychiatr Epidemiol 2006;41:868-74.

33. Hikichi H, Aida J, Tsuboya T, Kondo K, Kawachi I. Can community social cohesion prevent posttraumatic stress disorder in the aftermath of a disaster? A natural experiment from the 2011 Tohoku Earthquake and Tsunami. Am J Epidemiol 2016;183: 902-10.

34. Breslau N, Davis GC, Andreski P, Peterson E. Traumatic events and posttraumatic stress disorder in an urban population of young adults. Arch Gen Psychiatry 1991;48:216-22.

35. Davis L, Siegel LJ. Posttraumatic stress disorder in children and adolescents: a review and analysis. Clin Child Fam Psychol Rev 2000;3:135-54.

36. McNally RJ. Stressors that produce posttraumatic stress disorder in children. In: Davidson JRT, Foa EB, eds. Posttraumatic Stress Disorder: DSM-IV and Beyond. Washington, DC: American Psychiatric Press,1993;57-74.

37. Asarnow J, Glynn S, Pynoos RS, Nahum J, Guthrie D, Cantwell DP, et al. When the earth stops shaking: earthquake sequelae among children diagnosed for pre-earthquake psychopathology. J Am Acad Child Adolesc Psychiatry 1999;38:1016-23.

38. Garrison CZ, Bryant ES, Addy CL, Spurrier PG, Freedy JR, Kilpatrick DG. Posttraumatic stress disorder in adolescents after Hurricane Andrew. J Am Acad Child Adolesc Psychiatry 1995;34:1193-201.

39. Green BL, Korol M, Grace MC, Vary MG, Leonard AC, Gleser GC, et al. Children and disaster: age, gender, and parental effects on PTSD symptoms. J Am Acad Child Adolesc Psychiatry 1991;30:945-51.

40. Terr LC, Bloch DA, Michel BA, Shi H, Reinhardt JA, Metayer S. Children's symptoms in the wake of Challenger: a field study of distant-traumatic effects and an outline of related conditions. Am J Psychiatry 1999;156:1536-44.

41. Pfefferbaum B. The impact of the Oklahoma City bombing on children in the community. Mil Med 2001;166(12 Suppl):49-50.

42. Pfefferbaum B, Seale TW, Brandt EN Jr, Pfefferbaum RL, Doughty DE, Rainwater SM. Media exposure in children one hundred miles from a terrorist bombing. Ann Clin Psychiatry 2003;15:1-8.

43. Pfefferbaum B, Seale TW, McDonald NB, Brandt EN Jr, Rainwater SM, Maynard BT, et al. Posttraumatic stress two years after the Oklahoma City bombing in youths geographically distant from the explosion. Psychiatry 2000;63:35870.

44. Lee JY, Kim SW, Bae KY, Kim JM, Shin IS, Yoon JS. Factors associated with post-traumatic stress symptoms among adolescents exposed to the Sewol ferry disaster in Korea. Psychiatry Res 2017;256:391-95.

45. Silva RR, Alpert M, Munoz DM, Singh S, Matzner F, Dummit S. Stress and vulnerability to posttraumatic stress disorder in children and adolescents. Am J Psychiatry 2000;157:1229-35. 46. Stuber J, Fairbrother G, Galea S, Pfefferbaum B, Wilson- 
Genderson M, Vlahov D. Determinants of counseling for children in Manhattan after the September 11 attacks. Psychiatr Serv 2002;53:815-22.

47. Silverman WK, La Greca AM. Children experiencing disasters: definitions, reactions, and predictors of outcomes. In: La Greca AM, Silverman WK, Vernberg EM, Roberts MC, eds. Helping Children Cope with Disasters and Terrorism. Washington, DC:American Psychological Association,2002;11-33.

48. Swenson CC, Saylor CF, Powell MP, Stokes SJ, Foster KY, Belter RW. Impact of a natural disaster on preschool children: adjustment 14 months after a hurricane. Am J Orthopsychiatry 1996;66:122-30.

49. Morren M, Yzermans CJ, van Nispen RM, Wevers SJ. The health of volunteer firefighters three years after a technological disaster. J Occup Health 2005;47:523-32.

50. Stewart SH, Mitchell TL, Wright KD, Loba P. The relations of PTSD symptoms to alcohol use and coping drinking in volunteers who responded to the Swissair Flight 111 airline disaster. J Anxiety Disord 2004;18:51-68.

51. Hagh-Shenas H, Goodarzi MA, Dehbozorgi G, Farashbandi H. Psychological consequences of the Bam earthquake on professional and nonprofessional helpers. J Trauma Stress 2005; 18:477-83.

52. Cetin M, Kose S, Ebrinc S, Yigit S, Elhai JD, Basoglu C. Identification and posttraumatic stress disorder symptoms in rescue workers in the Marmara, Turkey, earthquake. J Trauma Stress 2005;18:485-9.

53. Dyregrov A, Kristoffersen JI, Gjestad R. Voluntary and professional disaster-workers: similarities and differences in reactions. J Trauma Stress 1996;9:541-55.

54. Herman D, Felton C, Susser E. Mental health needs in New York state following the September 11th attacks. J Urban Health 2002;79:322-31.

55. Blanchard EB, Rowell D, Kuhn E, Rogers R, Wittrock D. Posttraumatic stress and depressive symptoms in a college population one year after the September 11 attacks: the effect of proximity. Behav Res Ther 2005;43:143-50.

56. Başoğlu M, Kiliç C, Salcioğlu E, Livanou M. Prevalence of posttraumatic stress disorder and comorbid depression in earthquake survivors in Turkey: an epidemiological study. J Trauma Stress 2004;17:133-41.

57. Shalev AY, Tuval R, Frenkiel-Fishman S, Hadar H, Eth S. Psychological responses to continuous terror: a study of two communities in Israel. Am J Psychiatry 2006;163:667-73.

58. Thoresen S, Aakvaag HF, Wentzel-Larsen T, Dyb G, Hjemdal OK. The day Norway cried: proximity and distress in Norwegian citizens following the 22nd July 2011 terrorist attacks in Oslo and on Utøya Island. Eur J Psychotraumatol 2012. doi: 10.3402/ ejpt.v3i0.19709. [Epub ahead of print]

59. Yang HJ, Cheong HK, Choi BY, Shin MH, Yim HW, Kim DH, et al. Community mental health status six months after the Sewol ferry disaster in Ansan, Korea. Epidemiol Health 2015; 37:e2015046.

60. Caramanica K, Brackbill RM, Liao T, Stellman SD. Comorbidity of 9/11-related PTSD and depression in the World Trade Center Health Registry 10-11 years postdisaster. J Trauma Stress 2014;27:680-8.
61. Flory JD, Yehuda R. Comorbidity between post-traumatic stress disorder and major depressive disorder: alternative explanations and treatment considerations. Dialogues Clin Neurosci 2015;17:141-50.

62. Goldmann E, Galea S. Mental health consequences of disasters. Annu Rev Public Health 2014;35:169-83.

63. Agyapong VIO, Hrabok M, Juhas M, Omeje J, Denga E, Nwaka $\mathrm{B}$, et al. Prevalence rates and predictors of generalized anxiety disorder symptoms in residents of Fort McMurray six months after a wildfire. Front Psychiatry 2018;9:345.

64. Matsubara C, Murakami H, Imai K, Mizoue T, Akashi H, Miyoshi C, et al. Prevalence and risk factors for depressive reaction among resident survivors after the tsunami following the Great East Japan Earthquake, March 11, 2011. PLoS One 2014; 9:e109240.

65. Sharma A, Kar N. Posttraumatic stress, depression, and coping following the 2015 Nepal earthquake: a study on adolescents. Disaster Med Public Health Prep 2019;13:236-42.

66. Geng F, Zhou Y, Liang Y, Zheng X, Li Y, Chen X, et al. Posttraumatic stress disorder and psychiatric comorbidity among adolescent earthquake survivors: a longitudinal cohort study. J Abnorm Child Psychol 2019;47:671-81.

67. Kar N, Bastia BK. Post-traumatic stress disorder, depression and generalised anxiety disorder in adolescents after a natural disaster: a study of comorbidity. Clin Pract Epidemiol Ment Health 2006;2:17.

68. Blanchard EB, Buckley TC, Hickling EJ, Taylor AE. Posttraumatic stress disorder and comorbid major depression: is the correlation an illusion? J Anxiety Disord 1998;12:21-37.

69. Momartin S, Silove D, Manicavasagar V, Steel Z. Comorbidity of PTSD and depression: associations with trauma exposure, symptom severity and functional impairment in Bosnian refugees resettled in Australia. J Affect Disord 2004;80:231-8.

70. Shalev AY, Sahar T, Freedman S, Peri T, Glick N, Brandes D, et al. A prospective study of heart rate response following trauma and the subsequent development of posttraumatic stress disorder. Arch Gen Psychiatry 1998;55:553-9.

71. Chen YL, Lai CS, Chen WT, Hsu WY, Wu YC, Wang PW, et al. Risk factors for PTSD after Typhoon Morakot among elderly people in Taiwanese aboriginal communities. Int Psychogeriatr 2011;23:1686-91.

72. An Y, Fu G, Yuan G, Zhang Q, Xu W. Dispositional mindfulness mediates the relations between neuroticism and posttraumatic stress disorder and depression in Chinese adolescents after a tornado. Clin Child Psychol Psychiatry 2019;24:482-93.

73. Kane JC, Luitel NP, Jordans MJD, Kohrt BA, Weissbecker I, Tol WA. Mental health and psychosocial problems in the aftermath of the Nepal earthquakes: findings from a representative cluster sample survey. Epidemiol Psychiatr Sci 2018;27:301-10.

74. Pfefferbaum B, Stuber J, Galea S, Fairbrother G. Panic reactions to terrorist attacks and probable posttraumatic stress disorder in adolescents. J Trauma Stress 2006;19:217-28.

75. Boscarino JA, Adams RE. Peritraumatic panic attacks and health outcomes two years after psychological trauma: implications for intervention and research. Psychiatry Res 2009; 167:139-50.

76. Adams RE, Boscarino JA. A structural equation model of peri- 
event panic and posttraumatic stress disorder after a community disaster. J Trauma Stress 2011;24:61-9.

77. Tang W, Lu Y, Xu J. Post-traumatic stress disorder, anxiety and depression symptoms among adolescent earthquake victims: comorbidity and associated sleep-disturbing factors. Soc Psychiatry Psychiatr Epidemiol 2018;53:1241-51.

78. DiMaggio C, Galea S, Li G. Substance use and misuse in the aftermath of terrorism. A Bayesian meta-analysis. Addiction 2009;104:894-904.

79. Hirst A, Miller-Archie SA, Welch AE, Li J, Brackbill RM. Post-9/11 drug- and alcohol- related hospitalizations among World Trade Center Health Registry enrollees, 2003-2010. Drug Alcohol Depend 2018;187:55-60.

80. Boscarino JA, Kirchner HL, Hoffman SN, Sartorius J, Adams RE. PTSD and alcohol use after the World Trade Center attacks: a longitudinal study. J Trauma Stress 2011;24:515-25.

81. Welch AE, Caramanica K, Maslow CB, Brackbill RM, Stellman SD, Farfel MR. Trajectories of PTSD among lower Manhattan residents and area workers following the 2001 World Trade Center disaster, 2003-2012. J Trauma Stress 2016;29:158-66.

82. Pollice R, Bianchini V, Roncone R, Casacchia M. Marked increase in substance use among young people after L'Aquila earthquake. Eur Child Adolesc Psychiatry 2011;20:429-30.

83. Erskine N, Daley V, Stevenson S, Rhodes B, Beckert L. Smoking prevalence increases following Canterbury earthquakes. ScientificWorldJournal 2013;2013:596957.

84. Lee JY, Kim SW, Kang HJ, Kim SY, Bae KY, Kim JM, et al. Relationship between problematic internet use and post-traumatic stress disorder symptoms among students following the Sewol ferry disaster in South Korea. Psychiatry Investig 2017; 14:871-5.

85. Crum KI, Cornacchio D, Coxe S, Greif Green J, Comer JS. Conduct problems among Boston-area youth following the 2013 Marathon bombing: the moderating role of prior violent crime exposure. J Clin Child Adolesc Psychol 2017;46:343-52.

86. Pat-Horenczyk R, Peled O, Miron T, Brom D, Villa Y, Chemtob CM. Risk-taking behaviors among Israeli adolescents exposed to recurrent terrorism: provoking danger under continuous threat? Am J Psychiatry 2007;164:66-72.

87. Boer F, Smit C, Morren M, Roorda J, Yzermans J. Impact of a technological disaster on young children: a five-year postdisaster multiinformant study. J Trauma Stress 2009;22:51624.

88. Scott BG, Lapré GE, Marsee MA, Weems CF. Aggressive behavior and its associations with posttraumatic stress and academic achievement following a natural disaster. J Clin Child Adolesc Psychol 2014;43:43-50.

89. Lochman JE, Vernberg E, Powell NP, Boxmeyer CL, Jarrett M, McDonald K, et al. Pre-post tornado effects on aggressive children's psychological and behavioral adjustment through oneyear postdisaster. J Clin Child Adolesc Psychol 2017;46:136-49.

90. Liberty K, Tarren-Sweeney M, Macfarlane S, Basu A, Reid J. Behavior problems and post-traumatic stress symptoms in children beginning school: a comparison of pre- and post-earthquake groups. PLoS Curr 2016. doi: 10.1371/currents.dis. 2821c82fbc27d0c2aa9e00cff532b402.

91. Glodich A. Traumatic exposure to violence: a comprehensive review of the child and adolescent literature. Smith Coll Stud Soc Work 1998;68:321-45.

92. Fauerbach JA, Lawrence JW, Schmidt CW Jr, Munster AM, Costa PT Jr. Personality predictors of injury-related posttraumatic stress disorder. J Nerv Ment Dis 2000;188:510-7.

93. Cox BJ, MacPherson PS, Enns MW, McWilliams LA. Neuroticism and self-criticism associated with posttraumatic stress disorder in a nationally representative sample. Behav Res Ther 2004;42:05-14.

94. Chung MC, Easthope Y, Farmer S, Werrett J, Chung C. Psychological sequelae: post-traumatic stress reactions and personality factors among community residents as secondary victims. Scand J Caring Sci 2003;17:265-70.

95. Yin Q, Wu L, Yu X, Liu W. Neuroticism predicts a long-term PTSD after earthquake trauma: the moderating effects of personality. Front Psychiatry 2019;10:657.

96. Wu D, Yin H, Xu S, Zhao Y. Risk factors for posttraumatic stress reactions among Chinese students following exposure to a snowstorm disaster. BMC Public Health 2011;11:96.

97. Knezević G, Opacić G, Savić D, Priebe S. Do personality traits predict post-traumatic stress?: a prospective study in civilians experiencing air attacks. Psychol Med 2005;35:659-63.

98. Parslow RA, Jorm AF, Christensen H. Associations of pre-trauma attributes and trauma exposure with screening positive for PTSD: analysis of a community-based study of 2,085 young adults. Psychol Med 2006;36:387-95.

99. Guo W, Xue JM, Shao D, Long ZT, Cao FL. Effect of the interplay between trauma severity and trait neuroticism on posttraumatic stress disorder symptoms among adolescents exposed to a pipeline explosion. PLoS One 2015;10:e120493.

100. Costa PT Jr, McCrae RR. The five-factor model of personality and its relevance to personality disorders. J Pers Disord 1992;6: 343-59. 